\title{
3D Modelling of Coal Deformation under Fluid Pressure using COMSOL Multiphysics
}

\author{
Harinandan Kumar, ${ }^{1, *}$, M.K. Mishra ${ }^{2}$ and S.Mishra ${ }^{3}$ \\ ${ }^{1}$ Department of Mechanical Engineering Madanapalle Institute of Technolory \& Science, Madanapalle, Chittoor District, Andhra \\ Pradesh - 517325 \\ ${ }^{2}$ Department of Mining Engineering, NIT, Rourkela - 769008 \\ ${ }^{3}$ Department of Mining Engineering, NIT, Rourkela - 769008
}

Received 24 October 2017; Accepted 7 December 2017

\begin{abstract}
Gas transportation in coal bed is a complex physical process. The Adsorption/desorption process is associated with migration of gas in coal. Adsorption/desorption of $\mathrm{CO}_{2} / \mathrm{CH}_{4}$ in coal bed includes diffusion of gas from coal matrix and its flow through natural fractures. Therefore, it is necessary to have a clear concept of the flow behavior of gas in coal bed for successful coal bed methane (CBM) production and carbon dioxide sequestration. Flow of gas through natural cracks results in deformation of coal bed. Injection of $\mathrm{CO} 2$ in enhanced coal bed methane (ECBM) depends on the permeability and fluid flow behavior.Deformation in solid coal induced by fluid pressure during CBM and ECBM process is still not clearly understood. Numerical models and Multiphysics are dominant in modelling of complex study of flow induced deformation. Such modelling is required for detailed understanding of deformation as well as flow parameters. In this study 3D model of fractured coal core was developed. The deformation in coal core at multiple injected fluid pressures was analysed. Geo-mechanical parameters (Stress, Strain, Deformation, Pore pressure and Darcy's Velocity etc.) were determined at varying injection pressures. The relations between different Geo-mechanical parameters were established using a statistical approach.
\end{abstract}

Keywords: 3D modelling, Comsol Multiphysics, Geo-mechanical properties, Statistical Analysis

\section{Introduction}

Coal bed methane (CBM) is unconventional energy source. It comprises $95 \%$ pure methane with calorific value 8500 $\mathrm{Kcal} / \mathrm{g}$ (Zhang et al., 2015; Ojha et al., 2011). It is one of the promising technologies to fulfil the rapid increasing demand of energy. Methane resides in the coal matrix through sorption phenomena. Despite of gas in place of coal reservoir in depth knowledge of coal-gas interaction and flow induced deformation is important for successful and economical production of $\mathrm{CBM}$ as well as $\mathrm{CO}_{2}$ sequestration. Coal shows dual-porous nature with multiple sized pores (micro, meso and macro pores) that lower its permeability (Vandamme et al., 2010). CBM production and $\mathrm{CO}_{2}$ sequestration is very difficult for the reservoir with less understanding of gas transport phenomena (Swami and Settari, 2012). Importance of fluid transport and its impact on mechanical properties of coal bed have been studied elsewhere (Xiao et al., 2004; Yang and Zoback, 2011; Wang et al., 2012; Bigi et al., 2013; Ye et al., 2014; Ghanizadeh et al., 2014; Zhang et al., 2015). Diffusion of methane from the matrix and flow through the natural cracks (fractures and cleats) leads deformation in coal bed (Zhao and Jin, 1994; Wang et al., 2013; Liu et al., 2015). Migration of the gas within the matrix is driven by the concentration gradient while its flow through natural cracks is driven by the gas

\footnotetext{
*E-mail address: harinandankumar88@gmail.com

ISSN: 1791-2377 @ 2017 Eastern Macedonia and Thrace Institute of Technology. All rights reserved. doi:10.25103/jestr.106.09
}

pressure gradient (Andreas and Yves, 2011). Transportation of $\mathrm{CO}_{2} / \mathrm{CH}_{4}$ gases through coal at different pressure results swelling/shrinking of coal matrix. Deformation in coal matrix makes opening and closing of cleats more complicated (Chunguang et al., 2014).

In this paper 3D model of coal core was developed using Comsol Multiphysics 4.3. Poroelastic model was adopted for gas-solid coupling and determination of pressure induced deformation and change in mechanical properties. The model focuses on the elastic deformation in solid coal structure at different gas injection pressure. The poroelastic simulations were used for coupling of Darcy's flow with structural deformation. Experimentally evaluated input data for coal bed in Jharia coal field at a depth of $580 \mathrm{~m}$ was applied for analysis. The model was evaluated using Biotas well as pressure equation. The correlation between different Geo-mechanical properties and fluid pressure was established using a statistical approach.

\section{Geometry of Model}

The coal core representing the coal bed was developed using 3D modeling tool. The NX size of coal core of $54 \mathrm{~mm}$ diameter and $108 \mathrm{~mm}$ length with $\mathrm{L} / \mathrm{D}$ ratio 2 as per recommendation (ASTM, D2113-99) was considered for study (fig 1). Core was cut along the vertical axis to show the cleat structure clearly. The fractures of 1 to $2 \mathrm{~mm}$ wide and $1 \mathrm{~mm}$ deep were created in coal core to represent intact coal structure. 


\section{Numerical Modelling and Problem Description}

Uniform element formulation is possible for fractured rock by coupling fluid pressure and displacement ( $\mathrm{Li}$ and Ito, 2012; Lei et al., 2014). Simulations of porous material for fractures as well as matrix were carried out using flow equation to determine flow parameters and deformation in a material (Bai et al., 1999). In this investigation the fluidsolid coupling and pressure induced deformation was examined using numerical modeling and simulation. The model developed based on Biotporoelastic equation. It was developed in such a way that swelling occurs when the injecting pressure exceeds a limit. The input parameters applied for numerical simulation were determined experimentally as per ASTM and IS standards (Table 1). Compressive strength, Poisson's ratio and elastic modulus were determined as per IS: 9221-1979. A total of 3 to 5 samples from Jharia coal field at a depth of $580 \mathrm{~m}$ were taken for determination of geo-mechanical properties. Cohesion and angle of friction were determined using triaxial testing data. Permeability was determined as per pressure transient method. Porosity was calculated as per the established equation

$$
\gamma_{d}=\frac{G_{s} \cdot \gamma_{w}}{1+\frac{n}{1-n}}
$$

Where,

$\gamma_{d}=$ Dry unit weight,

$\gamma_{w}=$ Wet unit weight,

$\mathrm{G}_{\mathrm{s}}=$ Specific gravity,

$\mathrm{n}=$ Porosity

Specific gravity of powdered coal sample was determined using the pycnometer method as per IS: 2720 (Part-III)-1980. Finite element model was used to determine stress-strain, displacement and Darcy's velocity etc. of coal at different injecting fluid pressure. Stress - strain behavior of coal matrix was analyzed using the poroelastic model.

Table 1.Experimentally determined input parameters of Jharia coal field

\begin{tabular}{c|c}
\hline Elastic Modulus, E $(\mathrm{Gpa})$ & 1.70 \\
\hline Poisson's Ratio, $\mu$ & 0.36 \\
\hline Permeability, $\mathrm{K}(\mathrm{mD})$ & 0.52 \\
\hline Porosity $(\%)$ & 0.58 \\
\hline Cohesion, $\mathrm{C}_{0}(\mathrm{Mpa})$ & 0.90 \\
\hline Angle of friction, $\Phi(\mathrm{Degree})$ & 30 \\
\hline Compressive Strength, $\sigma_{\mathrm{c}}(\mathrm{MPa})$ & 4.20 \\
\hline Vertical Stress, $\sigma_{\mathrm{v}}(\mathrm{MPa})$ & 15.66 \\
\hline Horizontal Stress, $\sigma_{\mathrm{h}}(\mathrm{MPa})$ & 8.80 \\
\hline Depth $(\mathrm{m})$ & 580 \\
\hline
\end{tabular}

\section{Governing Equations and Boundary Conditions}

\subsection{Flow of Fluid}

In this investigation fluid flow was described by Darcy's Law in equation of continuity as

$$
\nabla \cdot\left(-\frac{K}{\mu} \cdot \nabla p\right)
$$

Where,

$\mathrm{K}=$ Permeability of coal,

$\mu=$ Dynamic viscosity of the fluid,

$\mathrm{p}=$ pore pressure

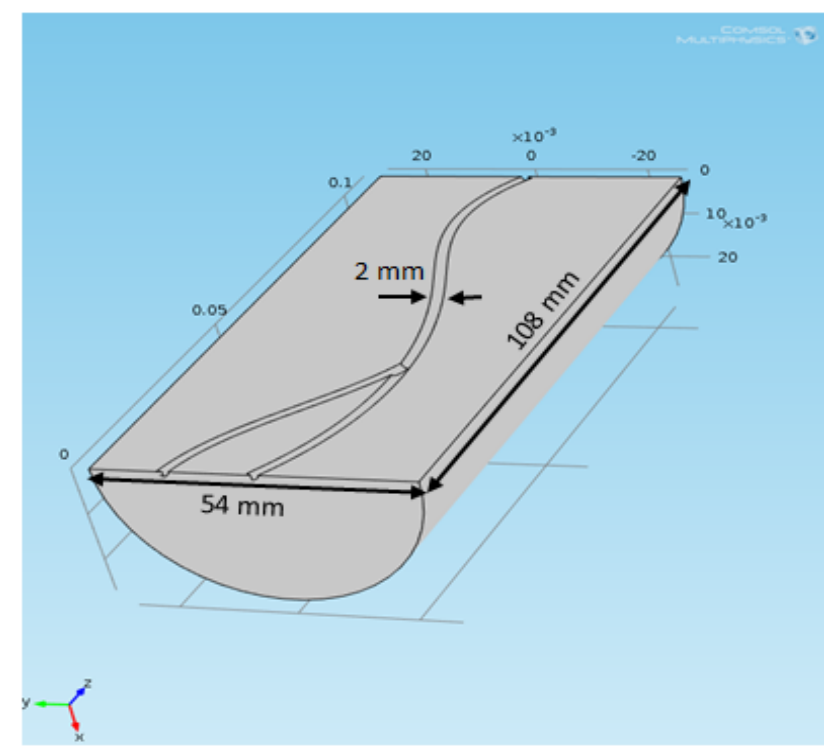

Fig. 1. 3D model of coal core sample

The flow boundaries spread from injecting point to the edge of the model. The upper and lower surface of the coal core is the planar surface and hence makes, symmetry boundary. The only passage of fluid is through the cleat so other domains were considered no flow domain and described as:

$p=p_{r}($ For Reservoir $)$

$n \cdot\left(-\frac{K}{\mu} \cdot \nabla p\right)=0$ (Symmetry face)

$n \cdot\left(-\frac{K}{\mu} \cdot \nabla p\right)=0($ Connectingsegments $)$

Where,

$\mathrm{n}=$ normal vector to the boundry, $\mathrm{p}_{\mathrm{r}}=$ Reservoir pressure

\subsection{Deformation Equation}

The deformation in coal was described by the system of equation as:

$$
-\nabla . \sigma=F
$$

Where, $\sigma$ denotes the stress tensor, and the directional components of the gradient in fluid pressure, $\mathrm{p}$, make up a vector forces, $\mathrm{F}$.

Biot Will's coefficient was considered 1 for this equation. The principal stress tensor was related to principal strain tensor as: 
$\varepsilon_{1}=\frac{1}{E} \cdot\left(\sigma_{1}-v\left(\sigma_{2}+\sigma_{3}\right)\right) ;\left[\varepsilon_{2}=\varepsilon_{3}=0\right]$

In matrix form the strain tensor is linearly related to stress tensor as:

$$
\varepsilon=D \cdot \sigma
$$

The element of 3D strain tensor depends on the element of displacement vectors as:

$$
\begin{aligned}
& \varepsilon_{x}=\frac{\partial u}{\partial x}, \varepsilon_{y}=\frac{\partial v}{\partial y}, \varepsilon_{z}=\frac{\partial w}{\partial z} \\
& \varepsilon_{x y}=\frac{1}{2}\left(\frac{\partial u}{\partial y}+\frac{\partial v}{\partial x}\right), \varepsilon_{y z}=\frac{1}{2}\left(\frac{\partial v}{\partial z}+\frac{\partial w}{\partial y}\right), \varepsilon_{x z}=\frac{1}{2}\left(\frac{\partial u}{\partial z}+\frac{\partial w}{\partial x}\right)
\end{aligned}
$$

The movement of all external boundaries was constrained under boundary conditions. The cleat area and internal matrix are only free to move. The equation for boundary conditions are summarized as:

$$
\begin{aligned}
& \mathrm{u}=\mathrm{v}=\mathrm{w}=0(\text { For outer surface) } \\
& \mathrm{u}=\mathrm{v}=0(\text { For edges) } \\
& \mathrm{u}=\mathrm{v}=\mathrm{w} \neq 0 \text { (For cleats and fractures) }
\end{aligned}
$$

According to Darcy's flow equation fluid experience variation in velocity as the pressure gradient exist in porous media. Thus the Darcy's velocity equation is as:

$$
u=\frac{K}{\mu} \cdot(\nabla P+\rho g \cdot \nabla D)
$$

Where, $\nabla P$ is pressure gradient, $\rho$ is fluid density, $\mathrm{g}=$ acceleration due to gravity, $\nabla D$ is the unit vector in the direction over which the gravity would take effect.

The 3D Coulomb failure criterion was considered for this model. The equation is written as:

$$
\begin{aligned}
& \text { fail }=\left(\sigma_{3}+P\right)-Q\left(\sigma_{1}+P\right)+N\left(1+\frac{\left(\left(\sigma_{2}-\sigma_{1}\right)\right)}{\sigma_{3}-\sigma_{1}}\right) \\
& Q=\frac{(1+\sin \varphi)}{(1-\sin \varphi)} \\
& N=\frac{(2 \cos \varphi)}{(1-\sin \varphi)} \cdot C
\end{aligned}
$$

Where, $\sigma_{1}, \sigma_{2}, \sigma_{3}$ are three principal stresses, $\mathrm{P}$ is the fluid pressure, $\mathrm{C}$ is coulomb cohesion and $\Phi$ is the angle of friction.

\section{Comsol Multiphysics and its Applications}

Studies on flow transport phenomena and numerical modeling using finite element method have gathered momentum in recent years (Suarez-Rivera et al., 2004; Vishal et al., 2012; Trivedi et al., 2012; Gupte et al., 2013). Validation of fluid flow and its impact on mechanical behavior of rock was done by experimental as well as numerical modeling (Pradhanet al., 2014; Vishalet al., 2015). Comsol model was implemented to study the flow behavior and displacement of oil through water pressure in porous media (Diaz-Viera et al., 2008). The relation between the permeability and properties of a realistic porous medium was determined using Navier-Stokes equation in comsol Multiphysics (Abdussamie, 2010). Fluid flow behavior, inter-molecular and gas-rock interactions in shale reservoir was investigated using comsol Multiphysics (Prajapati and Mills, 2014).Initiation and propagation of fractures in shale reservoir was studied at different injection pressure using poroelastic model in Comsol Multiphysics (Vishal et al., 2015). In this study open holemultilateral well modelbased on poroelastic formulation was considered for determination of flow behavior and deformation in coal. Geomechanicsmodule of Comsol Multiphysics 4.3 was applied for the formulation and numerical modeling. The experimentally obtained geo-mechanical parameters were provided as basic required data for modeling (Table 2). A precise flow of gas inside the cleats was assumed as per the equation:

$$
\frac{\nabla K}{\mu} \cdot(\nabla P)=0
$$

Table 2. Input parameters for Numerical Modeling

\begin{tabular}{c|c|c|c}
\hline Name & Value & Unit & Description \\
\hline $\mathrm{p} \_\mathrm{w}$ & 3 & $\mathrm{Mpa}$ & Pressure by fluid \\
\hline $\mathrm{p} \_\mathrm{r}$ & 15.66 & $\mathrm{Mpa}$ & Pressure in Reservoir \\
\hline $\mathrm{C}_{0}$ & 0.9 & $\mathrm{Mpa}$ & Coulomb cohesion \\
\hline $\mathrm{phi}$ & 30 & Degree & Friction angle \\
\hline $\mathrm{C}_{1}$ & 14.7 & -- & Calibration constant 1 \\
\hline $\mathrm{C}_{2}$ & 40 & -- & Calibration constant 2 \\
\hline $\mathrm{p}_{\mathrm{f}}$ & 5.13 & $\mathrm{Mpa}$ & Pressure in fracture \\
\hline
\end{tabular}

Carbon dioxide gas was considered as fluid to pass through the fractures and matrix. Fluid properties are shown in Table 3. Coal shows dual porosity nature with void and pores in its matrix hence porous material was chosen for the model with the properties given in Table 4 . The meshing of the 3D Model is generally very difficult due to small sized elements and high level of computing. In this modeling free triangular and tetrahedral elements type were considered for meshing (Fig 2). The meshing was finer to coarse depending on sharp to broad face as shown in Table 5 (Johnson, 1987; Zienkiewicz et al., 2005).

Table 3. Properties of fluid passing through model

\begin{tabular}{c|c}
\hline Density $\left(\mathrm{kg} / \mathrm{m}^{3}\right)$ & 400.17 \\
\hline Dynamic Viscosity (Pa.s) & $2.98 \mathrm{E}-05$ \\
\hline Fluid Compressibility $(1 / \mathrm{Pa})$ & 0.422445 \\
\hline
\end{tabular}

Table 4. Properties of material used for model 


\begin{tabular}{c|c}
\hline Elastic Modulus, E $(\mathrm{Gpa})$ & 1.7 \\
\hline Poisson's Ratio, $\mu$ & 0.36 \\
\hline Permeability, $\mathrm{K}(\mathrm{mD})$ & 0.52 \\
\hline Porosity $(\%)$ & 0.58 \\
\hline Density $\left(\mathrm{kg} / \mathrm{m}^{3}\right)$ & 1392.7 \\
\hline Biot Willi's Coefficient & 1 \\
\hline
\end{tabular}

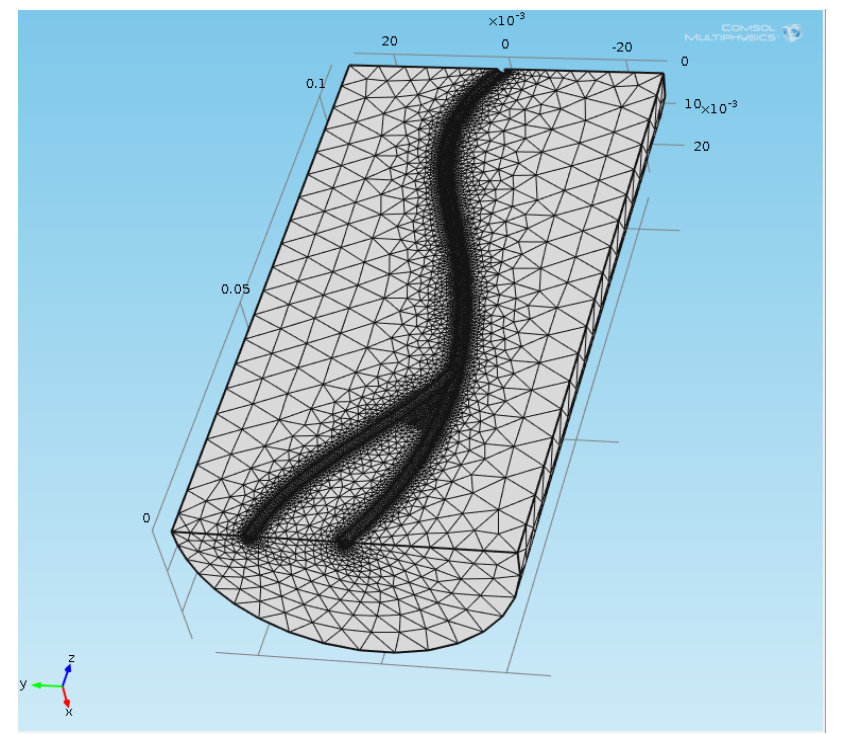

Fig. 2. Meshed 3D model with cleats and fractures

Table 5. Statistics of complete mesh of the model

\begin{tabular}{c|c}
\hline s & 103729 \\
\hline Triangular Element & 13640 \\
\hline Edge Element & 895 \\
\hline Vertex Element & 19 \\
\hline Minimum Element Quality & $6.10 \mathrm{E}-03$ \\
\hline Average Element Quality & 0.7215 \\
\hline Element Volume Ratio & $1.28 \mathrm{E}-05$ \\
\hline Mesh Volume & $1.23 \mathrm{E}-04$
\end{tabular}

Coal deformation and fluid flow behavior was determined as per the migration of fluid in the small opening (cleat) and pressure gradient. The mathematical expression depends on fluid pressure $\left(p_{-} w\right)$, reservoir pressure $\left(p_{-} r\right)$, coulomb cohesion $\left(\mathrm{C}_{0}\right)$, angle of friction $(\Phi)$ and pressure in fractures.

\section{Results and Discussion}

Computation was done as per given input parameters keeping all other values constant. Physico-mechanical properties were analysed at variable injecting fluid pressure from 1 to $10 \mathrm{MPa}$. An increase of $1 \mathrm{MPa}$ per run. $\mathrm{CO}_{2}$ gas was considered for determination of flow behavior and mechanical properties of coal in 3D modeling (Fig 3a). The elevated fluid pressure deformed the model and it swelled (Fig 3b). Colour contour helps to identify deformation at a particular instance of the model. The sharp deformation in all cases is found near the fracture while gentle away from fracture (Fig 3(a-b)). The deformation is noticed decreasing as going away from the fracture that confirms overall stability of the reservoir. The deformation occurred laterally as well as axially. The change in geo-mechanical parameters at deformed condition for each run was found out and correlated with fluid pressure. The lateral deformation was estimated from 0.10 to $0.124 \mathrm{~mm}$ while axial deformation was from 0.095 to $0.11 \mathrm{~mm}$ respectively for all runs. Deformation was found to increasing with increase in lateral distance (Fig 4a). Increment in lateral deformation was more up to $10 \mathrm{~mm}$ while the rate decreases later on (Fig 4a). But in case of an axial deformation rise and fall in curve is observed (Fig 4b). These changes are due to fractured model, material resistance and weakening of strain energy with distance. Correlation of lateral as well as axial deformation with fluid pressure was also established using the least square statistical method. Linear correlation with regression coefficient 0.82 and 0.95 respectively was observed (Fig 5(a-b)).

Principal strain for lateral as well as axial direction was also observed at variable injecting fluid pressure. First principal strain in lateral direction was found between 0.0049 and 0.0059 while second principal strain was from 0.0022 to 0.0025 respectively, for all run (Fig 6(a-b)). Similarly the First principal strain in axial was found between 0.0033 and 0.0039 and second principal strain was from 0.001 to 0.0013 respectively, for all run (Fig 6(c-d)).

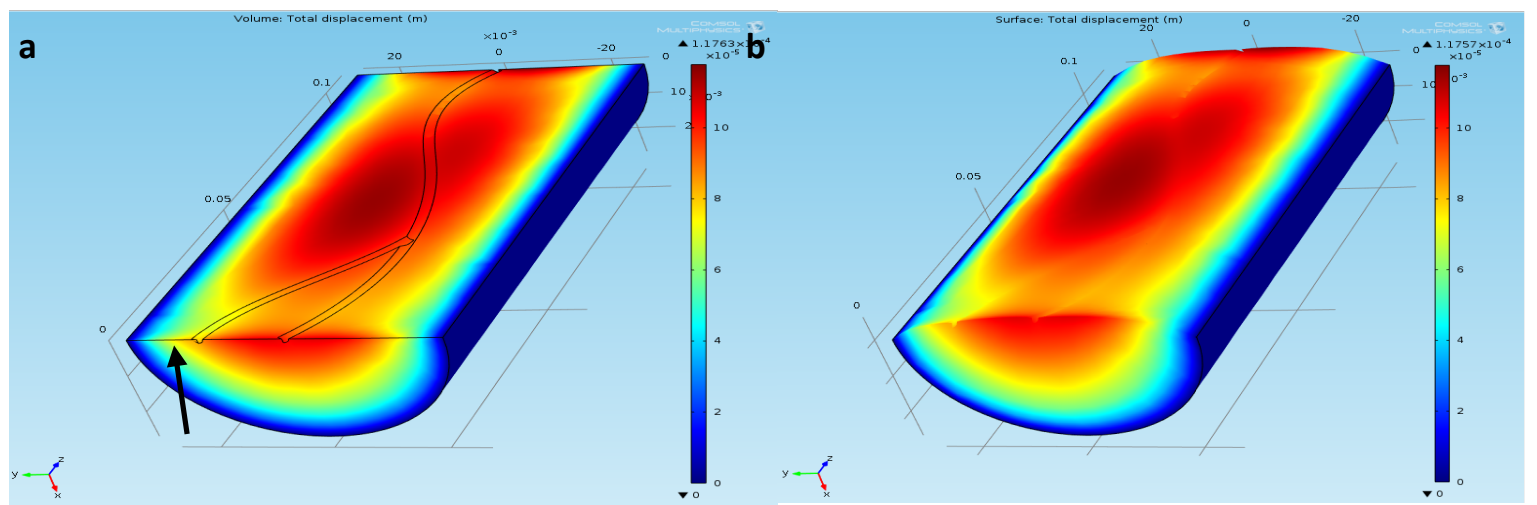

Fig. 3. 3D Model (a) undeformed with fractures (b) after deforming 
a

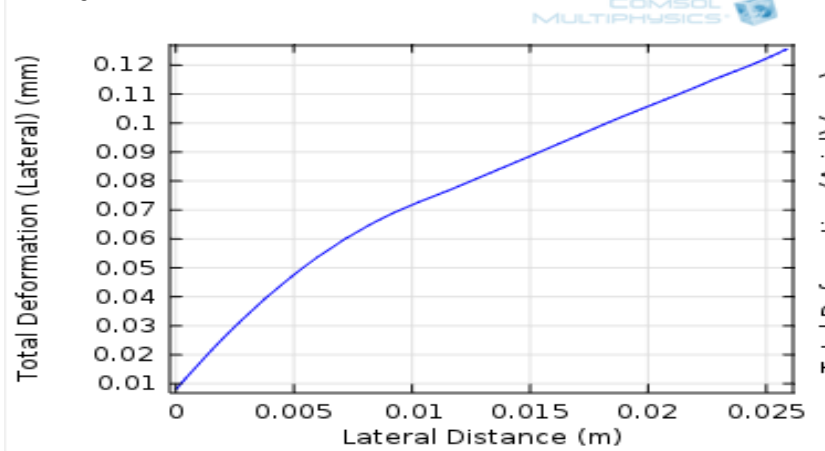

b

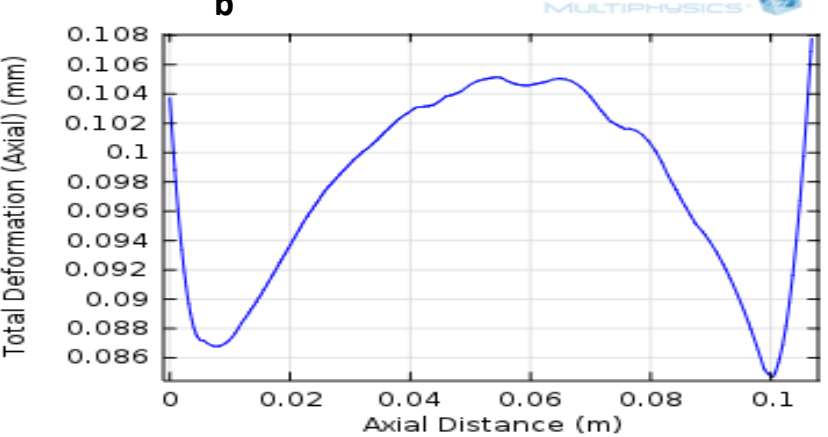

Fig. 4. (a) Lateral deformation experienced by the model at $10 \mathrm{MPa}$ fluid pressure(b) Axial deformation experienced by the model at $10 \mathrm{MPa}$ fluid pressure
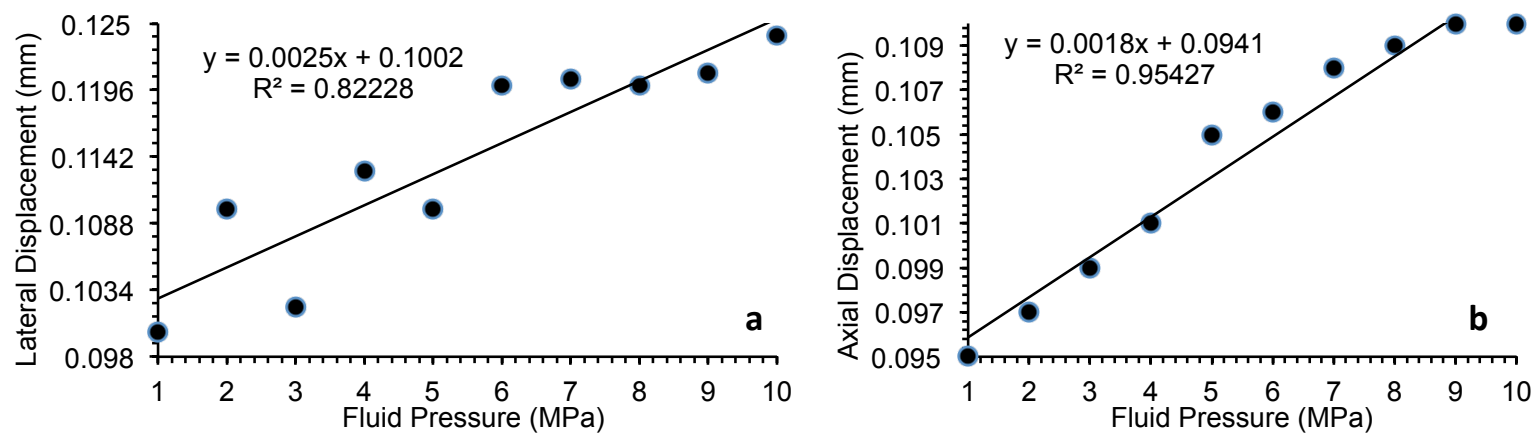

Fig 5. (a) Variation of lateral displacement with fluid pressure(b) Variation of Axial displacement with fluid pressure

The rise and fall of the curve is due to the presence of fractures and cleats in material and weakening of strain energy with distance. The principal strain is also correlated with fluid pressure. Linear correlation with $\mathrm{R}^{2} 0.96$ and 0.93 for lateral and 0.97 and 0.60 for axial strain respectively is observed (Fig 7(a-d).
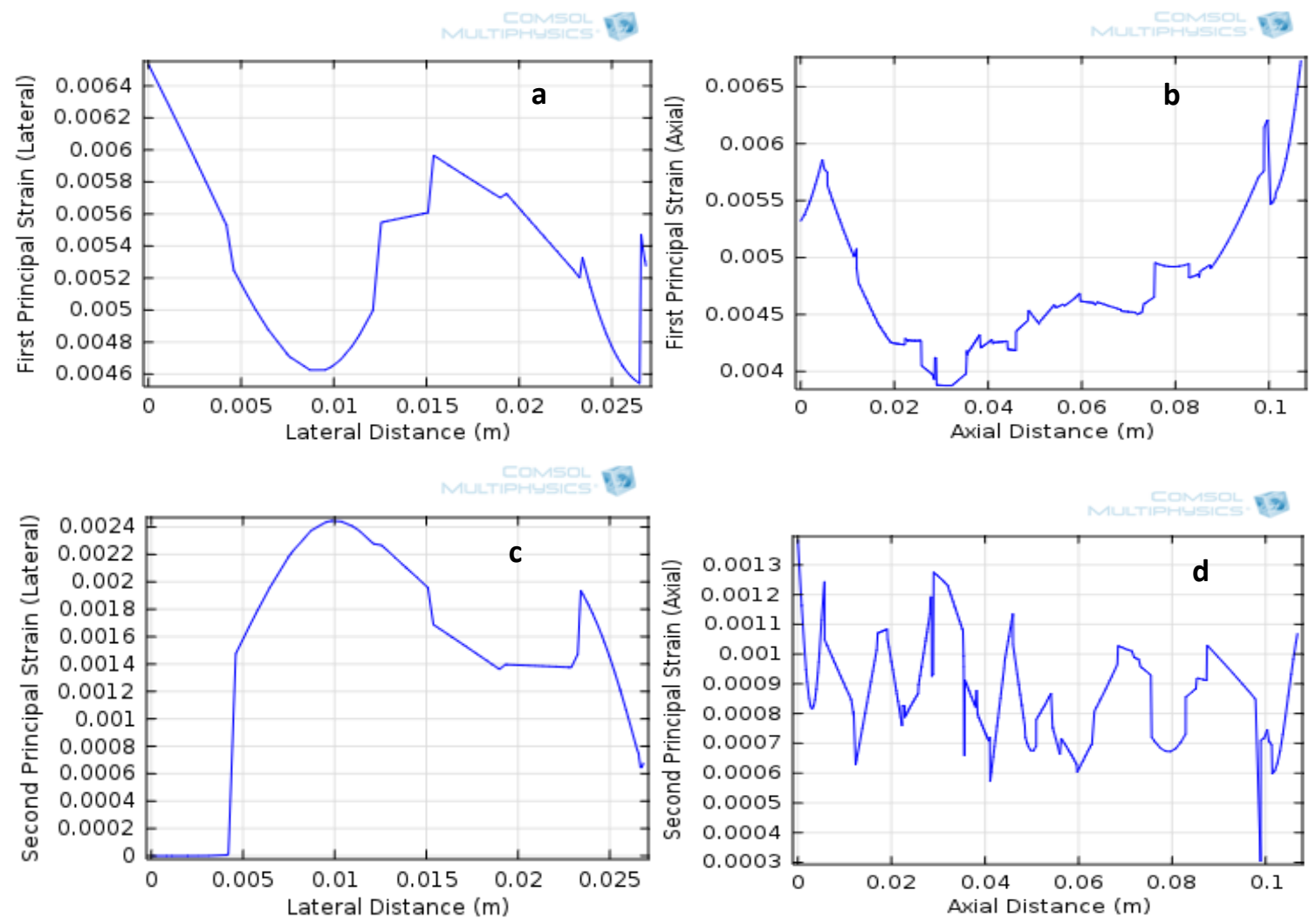

Fig. 6. Variation of strain with Lateral as well as axial distance (a) first principal strain with lateral distance (b) second principal strain with lateral distance (c) first principal strain with axial distance(d) second principal strain with axial distance. 

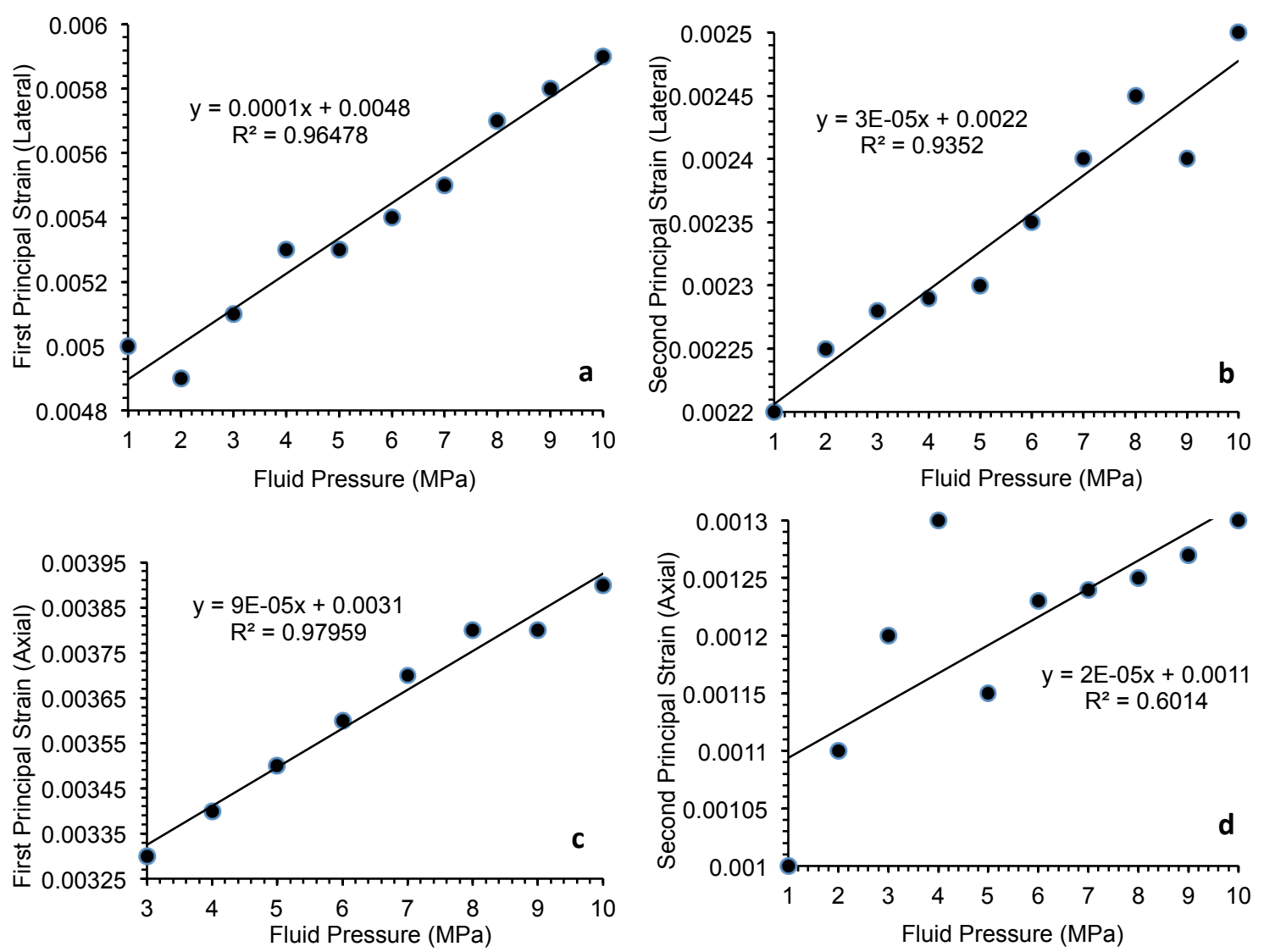

Fig. 7. Variation of (a) first principal strain (lateral) with fluid pressure (b) second principal strain (lateral) with fluid pressure (c) first principal strain (axial) with fluid pressure (d) second principal strain (axial) with fluid pressure

The movement of gas in fractured coal is not only in straight or forward, but also in transverse direction that causes the swelling or shrinkage of the coal matrix (Fig 8a). Darcy's velocity was computed at varying flow pressure. It is noticed that the streamline for velocity field is dense toward the transverse direction (Fig 8a). It applies pressure on wall surface leading to the swelling of material confirms the injection of gas at increasing pressure cause swelling of the coal matrix ((Fig 8(a-b)). Once the matrix swells the permeability and transportation of fluid adversely affected.
Continuous increasing in velocity was found up to $20 \mathrm{~mm}$ axial and lateral distance, but sudden rise and drop in velocity from 20 to $108 \mathrm{~mm}$ is due to cleat compression at higher fluid pressure (Fig 9(a-b)). Darcy's velocity in lateral direction was found from 5.3 to $32 \mathrm{~mm} / \mathrm{s}$ (Fig 10a) whereasit was in between 14 and $56 \mathrm{~mm} / \mathrm{s}$ respectively in axial direction (Fig 10b) for all run. This confirms the closing of cleats in fractured coal with increase in fluid injection pressure.

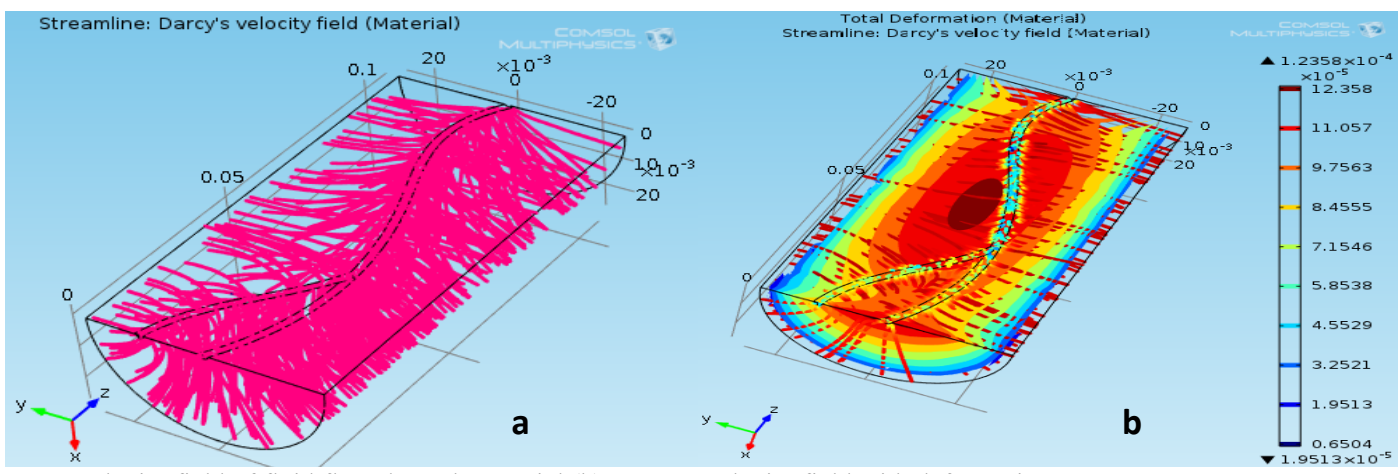

Fig. 8. (a) Darcy's velocity field of fluid flow through material (b) Darcy's velocity field with deformation contour

When Darcy's velocity was correlated with fluid pressure, $\mathrm{R}^{2}$ was found between 0.82 and 0.74 in lateral as well as axial direction respectively (Fig 10 (a and b)), obeying Power correlation in curve fitting.

Pore pressure is important for the determination of permeability as well as gas transportation in cleat structure and matrix of coal. Pore pressure was found to increasing with increase in lateral distance (Fig 11a). It varies from 15.5 to $15.95 \mathrm{MPa}$ for all run (Fig 11b). Strong linear correlation was found between pore pressure and fluid pressure with $\mathrm{R}^{2} 0.95$. 


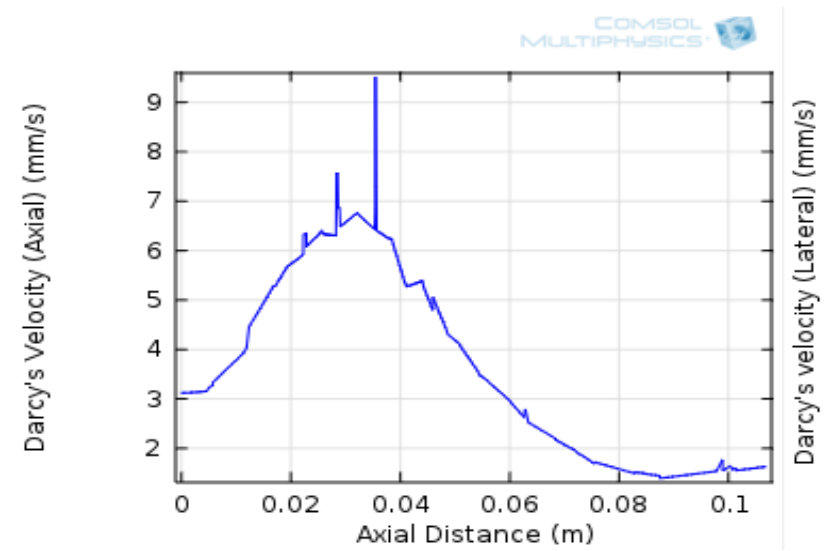

a)

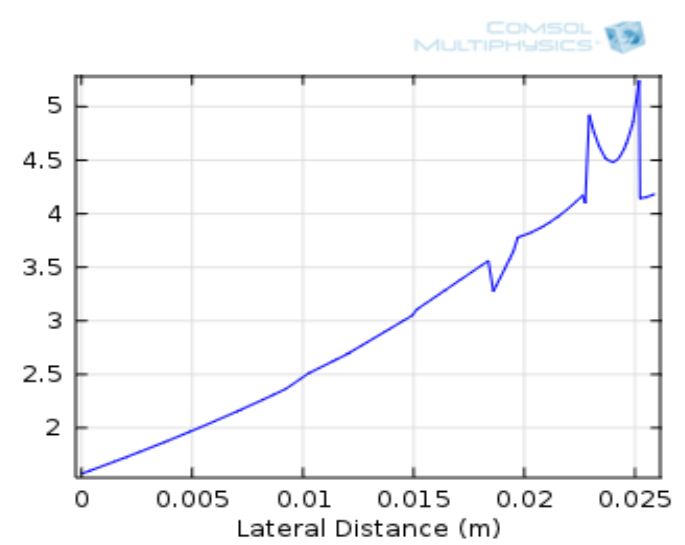

b)

Fig. 9. Variation of Darcy's velocity with (a) lateral distance (b) axial distance

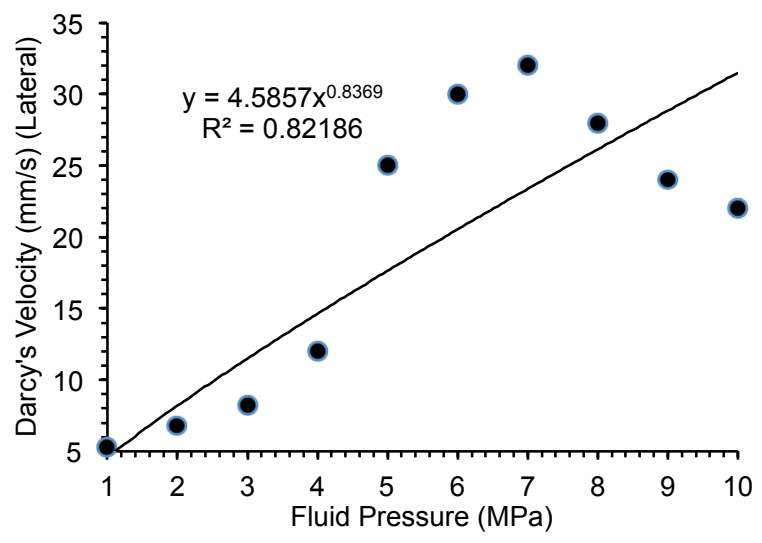

a)

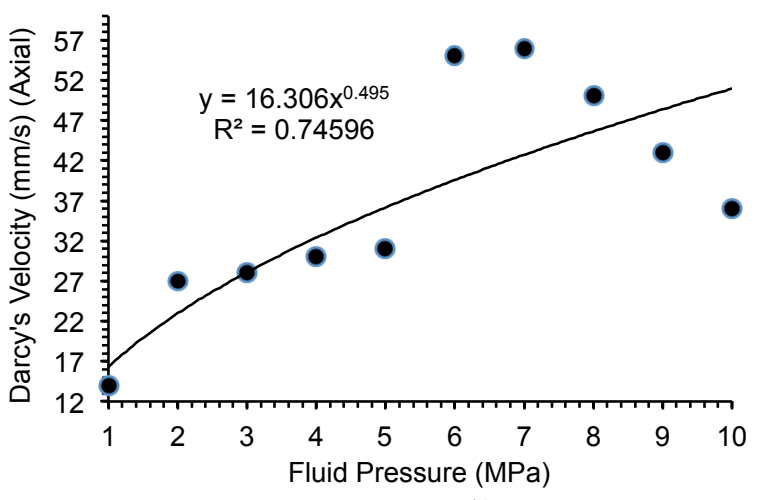

b)

Fig. 10. Variation of fluid pressure with(a) Darcy's velocity (lateral) (b) Darcy's velocity (axial)

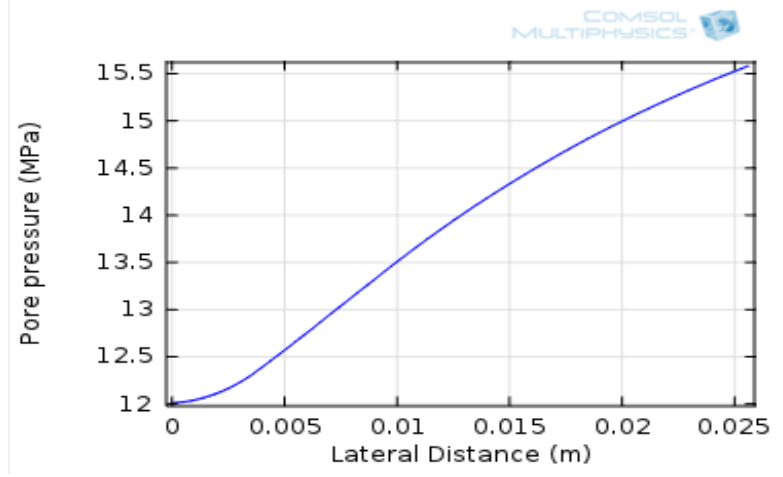

a)

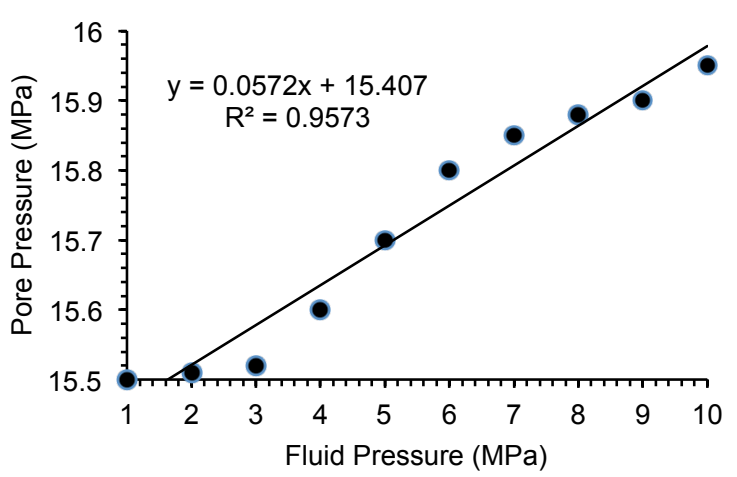

b)

Fig 11. Variation of fluid pressure with (a) Darcy's velocity (lateral) (b) Darcy's velocity (axial)

\section{Conclusion}

The paper discusses the gas transport behavior and pressure induced deformation in fractured coal core representing jharia coal at the depth of $580 \mathrm{~m}$ using $3 \mathrm{D}$ modeling approach. The gas-solid coupling is discussed based on poroelastic model. The study indicates

- Fluid flow behavior in fractured coal can be analysed using 3D modeling.

- Change in mechanical properties (deformation, stress and strain etc.) of the coal matrix due to fluid pressure can be estimated using numerical methods.

- Darcy's velocity of gas $\left(\mathrm{CO}_{2}\right)$ varies from 5.3 to $32 \mathrm{~mm} / \mathrm{s}$ (lateral) and 14 and $56 \mathrm{~mm} / \mathrm{s}$ (axial) respectively at 1 to 10 $\mathrm{MPa}$ fluid pressures. It shows power correlation with $\mathrm{R}^{2}$
0.82 (lateral) and 0.74 (axial) respectively, when correlated with fluid pressure.

- The lateral deformation was found from 0.10 to $0.124 \mathrm{~mm}$ while axial deformation was from 0.095 to $0.11 \mathrm{~mm}$ respectively, for fluid pressure from 1 to $10 \mathrm{MPa}$. Linear correlation with $\mathrm{R}^{2} \quad 0.82 \quad$ (lateral)and $0.95 \quad$ (axial) respectively was observed as correlated with fluid pressure.

- First principal lateral strain varies from 0.0049 and 0.0059 while second principal lateral strain varies from 0.0022 to 0.0025 respectively, for fluid pressurefrom 1 to $10 \mathrm{MPa}$. Linear correlation with $\mathrm{R}^{2} 0.96$ (lateral) and 0.93 (axial) respectively, was observed as correlated with fluid pressure.

- First principal axial strain varies from 0.0033 to 0.0039 while second principal axial strain varies from 0.001 to 
0.0013 respectively for fluid pressure from 1 to $10 \mathrm{MPa}$. Linear correlation with $\mathrm{R}^{2} 0.97$ (lateral) and 0.60 (axial) respectively, was observed as correlated with fluid pressure.

- Pore pressure varies from 15.5 to $15.95 \mathrm{MPa}$ for fluid pressure 1 to $10 \mathrm{MPa}$. It shows linear correlation with $\mathrm{R}^{2}$ 0.95 (lateral) when correlated with fluid pressure.
This is an Open Access article distributed under the terms of the Creative Commons Attribution Licence

\section{References}

1. M. Vandamme, L. Brochard, B. Lecampion, O. Coussy,"Adsorption and strain: the $\mathrm{CO}_{2}$-induced swelling of coal", J. Mech Phys. Solids, Vol. 58, pp 1489-1505, 2010

2. B. Andreas and G. Yves, "CBM and $\mathrm{CO}_{2}$-ECBM related sorption processes in coal: a review", Int. J. of Coal Geol., Vol. 87, pp 4971, 2011

3. C. Wang, M. Wei, B. Gong, Y. Tan, "Deformation transition of intact coal induced by gas injection", International Journal of Mining Science and Technology, Vol. 24, pp. 833-838, 2014

4. Yongbin Zhang, Bin Gong, Junchao Li, Hangyu Li, "Discrete Fracture Modeling of 3D Heterogeneous Enhanced Coalbed Methane Recovery with Prismatic Meshing", Energies, Vol. 8, pp. 6153-6176, 2015

5. K. Ojha, B. Karmakar, A. Mandal, A. K. Pathak, "Coal Bed Methane in India: Difficulties and Prospects", International Journal of Chemical Engineering and Applications, Vol. 2, pp. 256-260, 2011

6. Q. Liu, Y. Cheng, H. Zhou, P. Guo, F. An, H. Chen, "A Mathematical Model of Coupled Gas Flow and Coal Deformation with Gas Diffusion and Klinkenberg Effects", Rock Mech. Rock Engg., Vol. 48, pp. 1163-1180, 2015

7. S. Wang, D. Elsworth, J. Liu, "Permeability evolution during progressive deformation of intact coal and implications for instability in underground coal seams", International Journal of Rock Mechanics \& Mining Sciences, Vol. 58, pp. 34-45, 2015

8. Y. Zhao and Z. Jin, "Mathematical model for coupled soliddeformation and methane flow in coal seams", Appl. Math. Modelling,, Vol. 18, pp. 328-333, 1994

9. V. Swami, A. Settari, "A pore scale gas flow model for shale gas reservoir" Society of Petroleum Engineers (SPE), Americas Unconventional Resources Conference, Pittsburgh, Pennsylvania, USA. SPE Paper 155756, 2012

10. Y. Yang and M. D. Zoback, "The Effects of Gas Adsorption on Swelling, Visco-plastic Creep and Permeability of Sub-bituminous Coal", $45^{\text {th }}$ US Rock Mechanics/Geomechanics Symposium, 2011

11. G. Xiao, F. Yu, D. Zhimin, S. Zhuangzhi, "Coupled Flow Simulation in Coalbed Methane Reservoirs", SPE Eastern Regional Meeting, 15-17 September, Charleston, West Virginia, 2004

12. Z. Ye, D. Chen, J. G. Wangb, "Evaluation of the non-darcy effect in coalbed methane production", Fuel, Vol. 121, pp. 1-10, 2014

13. A. Ghanizadeh, A. Amann-Hildenbrand, M. Gasparik, G. Yves, B. M. Krooss, R. Littke, "Experimental study of fluid transport processes in the matrix system of the European organic-rich shales: II. Posidonia Shale (Lower Toarcian, northern Germany)", International Journal of Coal Geology, Vol. 123, pp. 20-33, 2014

14. S. Bigi, M. Battagliaa A. Alemannib, S. Lombardia, A. Campanac, E. Borisovac, M. Loizzoc, " $\mathrm{CO}_{2}$ flow through a fractured rock volume: Insights from field data, 3D fractures representation and fluid flow modeling", International Journal of Greenhouse Gas Control, Vol. 18, pp. 183-199, 2013

15. J. G. Wang, A. Kabir, J. Liu, Z. Chen, "Effects of non-darcy flow on the performance of coal seam gas wells", International Journal of Coal Geology, Vol. 93, pp. 62-74, 2012

16. X. L. Lei, X. Y. Li and Q. Li., "Insights on injection-induced seismicity gained from laboratory AE study - Fracture behavior of sedimentary rocks", $8^{\text {th }}$ Asian Rock Mechanics Symposium, Sapporo, Japan, 2014

17. Q. $\mathrm{Li}$ and $\mathrm{K}$. Ito, "Analytical and numerical solutions on the response of pore pressure to cyclic atmospheric loading: With application to Horonobe underground research laboratory", Japan. Environ. Earth Sci., Vol. 65, pp. 1-10,2012

18. M. Bai, F. Meng, D. Elsworth, J. C. Roegiers, "Analysis of stressdependent permeability in nonorthogonal flow and deformation fields", Rock Mech. Rock Engg., Vol. 32, pp. 195-219, 1999

19. M. A. Diaz-Viera, D. A. Lopez-Falcon, A. Moctezuma-Berthier, A. Ortiz-Tapia, "COMSOL Implementation of a Multiphase Fluid Flow Model in Porous Media,InstitutoMexicano del Petroleo, Excerpt from the Proceedings of the COMSOL Conference, 2008

20. N. Abdussamie, "Navier-Stokes Solutions for Flow and Transport in Realistic Porous Media", Excerpt from the Proceedings of the COMSOL Conference, 2010

21. N. J. Prajapati and P. L. Mills, "Numerical Study of Flux Models for $\mathrm{CO}_{2}$ : Enhanced Natural Gas Recovery and Potential $\mathrm{CO}_{2}$ Storage in Shale Gas Reservoirs", Excerpt from the Proceedings of the COMSOL Conference, 2014

22. V. Vishal, N. Jain, T. N. Singh, "Three dimensional modelling of propagation of hydraulic fractures in shale at different injection pressures", Sustain. Environ. Res., Vol. 25, pp. 217-225, 2015

23. O. C. Zienkiewicz, R. L. Taylor and P. Nithiarasu, "The Finite Element Method for Fluid Dynamics", $6^{\text {th }}$ Ed., Elsevier, Waltham, 2005

24. C. Johnson, "Numerical Solution of Partial Differential Equations by the Finite Element Method", Cambridge University Press, 1987

25. R. Suarez-Rivera, B. J. Begnaud and J. W. Martin, "Numerical analysis of open-hole multilateral completions minimizes the risk of costly junction failures", Rio Oil \& Gas Expo and Conference. Rio de Janeiro, Brazil, 2004

26. V. Vishal, T. N. Singh and P. G. Ranjith, "Carbon capture and storage in Indian coal seams", Carbon Management Technology Conference, Orlando, 2012

27. IS : 9221, "Indian Standard Method for Determination of Modulus of Elasticity and Poisson's Ratio of Rock Materials in Uniaxial Compression", 1979

28. IS: 2720-3-1, "Methods of test for soils, Part 3: Determination of specific gravity, Section 1: Fine grained soils", 1980

29. ASTM: D 2113-99, "Standard Practice for Rock Core Drilling and Sampling of Rock for Site Investigation”, PP. 7, 1999 